\title{
THE VIRTUE OF HONESTY, NAZIS AT THE DOOR, AND HUCK FINN CASES
}

\begin{abstract}
I begin by outlining some of the central conceptual features of the virtue of honesty. But the real focus of the paper is on seeing how my account of honesty can handle certain challenging cases. One case is the "Nazi at the door" example. The other is Mark Twain's Huck Finn, who seemed to think that what he was doing in helping Jim was morally wrong, and yet we would be reticent to count it as a case of failing to be honest. I argue that my proposed account of honesty can recommend plausible ways to think about both of these famous cases.
\end{abstract}

Keywords: Honesty, Huck Finn, Lying, Cheating, Stealing, Virtue, Character, Misleading.

In recent years, philosophers have had plenty to say about certain virtues. Modesty is one of them. Compassion is another. Self-control is a third. ${ }^{1}$

Honesty? Not so much. Indeed, as far as I am aware, only two papers on honesty have appeared in philosophy journals in the last 40 years. $^{2}$

My current research is trying to remedy this situation. In several papers, an edited volume, and a book manuscript, I am trying to direct philosopher's attention to this stunningly neglected virtue and many of the very interesting issues that arise in discussing it. ${ }^{3}$

This paper gets to the heart of this project by outlining an account of the central conceptual features of the virtue of honesty. That happens in section

1 For an example of each, see Driver 1989, Caouette and Price 2018, and Mele 1995, respectively.

2 Smith 2003 and Wilson 2018. There are also a few brief discussions of honesty in monographs, such as MacIntyre 1981.

To some extent the lack of attention to honesty is also found in other fields such as personality psychology, although there has been more work done recently in positive psychology and also using the HEXACO personality trait framework.

3 See Miller 2017, in progress, and Miller and West forthcoming. Some of the interesting issues arise with respect to other virtues as well, but many are specific to the virtue of honesty, such as whether it has a vice of excess, and whether a pluralist theory of motivation is the best way to go. 
one. The remainder of the paper is devoted to seeing how the account can handle certain challenging cases. Section two focuses on "Nazi at the door" examples. Section three turns to cases like Huck Finn, who seemed to think that what he was doing in helping Jim was morally wrong, and yet we would be reticent to count it as a case of lack of honesty. I ultimately conclude that my proposed account of honesty can recommend plausible ways to think about both of these famous cases.

\section{The Account of Honesty}

The central notion at work in my account is reliably not intentionally distorting the facts. An honest person, in other words, is someone who is disposed to reliably not intentionally distort the facts, both to herself or to other people.

I do not have an analysis to offer of "distorting" in this context, and I am doubtful that an informative and reductive account could even be given. But a close synonym to what I have in mind is captured by "misrepresentation" - an honest person is someone who is disposed to not intentionally misrepresent the facts, either to herself or to other people. ${ }^{4}$

I can say more about "intentionally." In some contexts, "intentionally" could be understood as "intending" or "as a result of an intention." 5 The relevant contrast would be "not as part of a plan." So the proposal would amount to saying that an honest person reliably does not plan to distort the facts.

But that is not the sense of "intentionally" I have in mind. My usage includes planning and acting from an intention, but it is broader since it includes other mental states as well, such as wants, wishes, emotions, feelings, and the like. Actions results from these mental states need not always be done as part of a plan. Furthermore, "intentional action" on my usage can be causally influenced by subconscious mental states.

So the relevant contrast to "intentionally," as I am using the term here, is "accidentally." If by accident a banana happens to fall into someone's pocketbook at the grocery store and she walks out without paying, she is not intentionally distorting the facts in my sense. Similarly while playing a board game, if no one notices that the players went out of order in a way that benefited one of the them, then that also would not be intentionally distorting the facts. On the flip side, cheating or stealing that is influenced by unconscious psychological states could count as intentional, and so could also count as dishonest in my sense. This would be the case, even if the person

4 For a similar claim, see Guenin 2005: 222.

5 For discussion see Bratman 1987. I am grateful to Walter Sinnott-Armstrong for helpful discussion. 
didn't recognize those states consciously or they didn't play a conscious role in her planning.

What about "reliably"? Well, clearly someone who refrains from intentionally distorting the facts just once or twice out of hundreds of opportunities does not count as honest. "Reliably" is the label I will use for both stability over time and consistency across situations. Stably over time, the honest lawyer does not intentionally distort the facts in the courtroom. But if she is an honest person, and not just an honest lawyer, then she typically refrains from distorting the facts at home, at the gym, at the stores, and so forth. To be fair, honesty comes in degrees, and she does not have to be perfectly reliable in order to count as honest. Which is good news, as otherwise the virtue of honesty would be incredibly difficult to instantiate.

With these clarifications in mind, I suggest we consider the following as an initial proposal for characterizing the virtue of honesty:

(H1) The virtue of honesty is, centrally, a character trait concerned with reliably not intentionally distorting the facts. ${ }^{6}$

Note that (H1) does not purport to offer necessary and sufficient conditions. It rather seeks to illuminate central conceptual features of the virtue.

Finally, let me turn to the "facts." My preference is to not presuppose any account of "facts" in (H1), but rather to keep the proposal as ecumenical as possible. That $2+2=4$, that the Earth is round, and that I am not a unicorn are all "facts" on a standard usage of that term. Facts have to be the case and have to capture the way the world really is. But that is compatible with facts being abstract or concrete objects, propositions or the referents of propositions, and the like.

It is not a fact that the Earth is flat. But it is a fact that people used to believe that the Earth is flat (and some people still do!). This is a perfectly natural way to talk about facts. But there are limits. My usage does not allow for "alternative facts," to use the expression which originated with Donald Trump's advisor Kellyanne Conway in 2017. There is only one way the facts are.

(H1) is formulated in terms of the facts, not in terms of the agent's beliefs about the facts. Which is the right way to go? In other words, does honesty

6 For a broadly similar proposal, see Smith 2003: 518, 520. As Smith writes, "Honesty is a refusal to fake reality. It is a person's refusal to pretend that facts are other than they are, whether to himself or others" (518).

An anonymous reviewer asked why I didn't develop the account in terms of "lack of deception." The main reason is that I am trying to provide a more informative account than that would end up being. An additional reason depends upon what one thinks about bald-faced lies, theft, and cheating. If they can still be instances of a failure of honesty even though there is no intention to deceive, then a "lack of deception" approach will be inadequate. 
require reliable epistemic access to the facts, or is it enough to just not distort the facts as the agent takes them to be?

The latter option seems more plausible to me. Here are two cases that I find persuasive in illustrating why:

The Flat Earth Society. As a member of the Flat Earth Society, Samantha sincerely believes that the Earth is flat. One day she is asked by a friend about the shape of the Earth, and to keep her own beliefs a secret, Samantha tries to mislead her friend and replies that the Earth is round. She succeeds and her friend now assumes that Samantha believes the Earth is round.

Now suppose instead that Samantha is forthright. She tells her friend that she believes the Earth is flat, and has no intention to mislead her friend at all.

It seems to me that in the first version Samantha succeeded in lying, and exhibited a failure of honesty in this case. In the second version, it seems to me that, even though her belief is false, Samantha exhibits honesty in this case.

Not in the Library. Saul tells his mother that he was studying at the library last night, with the intention of misleading her about what he was really doing. He believes that he had actually spent the night at Rachel's apartment. Unbeknownst to him, the person he was spending time with was not named "Rachel" and it was not her apartment.

Suppose instead that, with no intention of misleading her, Saul told his mother that he was spending time at Rachel's apartment last night.

It seems to me that in the first version Saul succeeded in lying, and exhibited a failure of honesty in this case. In the second version, it seems to me that, even though his belief is false, Saul exhibits honesty in this case. ${ }^{7}$

The lesson I take away from cases like these is that both honesty and dishonesty are not tied down to veridical representations of the facts. ${ }^{8}$ What we have are different possibilities being exhibited:

(False Belief + False Assertion) leading to Honest Action

7 Note that this discussion is about isolated actions, not about the person's trait of honesty or dishonesty. So even if Samantha and Saul failed to exhibit honesty in the first version of the cases, that is entirely compatible with their still being honest people in general. Nevertheless, (H1) has a story to tell about what it is to exhibit or fail to exhibit honesty in a given instance of behavior, and if that story is problematic (as I am suggesting it is), that is grounds for revising (H1) itself. Thanks to an anonymous reviewer for suggesting I clarify this point.

$8 \quad$ For related discussion, see Fried 1978: 58 


$\begin{array}{lll}\text { (False Belief }+ \text { True Assertion) } & \text { leading to } & \text { Dishonest Action } \\ \text { (False Belief + True Assertion) } & \text { leading to } & \text { Dishonest Action }\end{array}$

It is already obvious that there are cases in which we find these combinations:
(True Belief + True Assertion)
leading to
Honest Action
(True Belief + False Assertion)
leading to
Dishonest Action

So given that honest actions don't require that the beliefs of the agent in question be true, we need to revise (H1). In other words, we need an account which ties honesty to subjective representations of the facts, not to the objective facts themselves:

(H2) The virtue of honesty is, centrally, a character trait concerned with reliably not intentionally distorting the facts as the agent sees them. ${ }^{9}$

Even though it will undergo additional refinement elsewhere, ${ }^{10}(\mathrm{H} 2)$ is the core account of the virtue of honesty that I wish to defend.

As a character trait, honesty is a set of psychological dispositions which, when activated, give rise to thoughts and feelings that, in turn and other things being equal, lead the person in question to reliably not intentionally distort the facts as she sees them. What this looks like more specifically will depend on what kind of behavior we are talking about. To illustrate, let's take lying first. When (H2) is applied to lying, we get:

Lying: An honest person reliably does not intentionally distort the facts as she sees them by telling lies to others. Nor would she distort the facts about herself in lying to herself either. ${ }^{11}$

If Smith tells his teacher that the dog ate his homework, when Smith in fact never bothered to do it in the first place, then he is intentionally distorting the facts about his homework with the intention of trying to deceive his teacher. Indeed, if the lie is successful, Smith will have distorted the facts in more than one way. His teacher will now believe that the dog ate his homework. And the teacher will now believe that Smith believes that the dog

9 There are the facts as the person consciously believes them to be, and there are the facts as the agent really believes them to be, but does not consciously recognize due to selfdeception or the like. (H2) needs to be refined to take into account such a distinction. See Miller in progress for more details.

10 Miller in progress.

11 For an approach along these lines, see Bok 1978: chapter two. See also MacIntyre: "Truthful persons...do not misrepresent themselves to others as liars do, with regard to the relationship of their beliefs and their intentions to their assertions" (1994: $314)$. 
ate his homework. Both of these beliefs, however, are false. ${ }^{12}$ We see similar distortions at work when a media outlet lies about a political candidate's past behavior, or when a political candidate himself lies about that behavior. They are intentionally distorting the facts. Cases of lying fit comfortably with the framework outlined here.

The homework example serves to bring out just how distorting successful lies can be. Obviously with respect to what is being stated, they aim to distort the facts by the lights of the person who is lying. But in the process they also, if successful, distort the facts with respect to how the audience views the beliefs of the liar. Indeed, when the liar says something that, unbeknownst to him, is actually true, then there is no distortion of the facts in the audience's mind with respect to the content of what has been said. But there still remains the distortion that comes from the audience forming mistaken beliefs about what the speaker really believes. This arises from the liar intentionally distorting or misrepresenting his own psychology.

In addition to lying, the same goes for misleading others:

Misleading: An honest person reliably does not intentionally distort the facts by her own lights by withholding important information, telling half-truths involving misleading details, or acting in such a way intentionally so as to get others to arrive at a false belief.

Consider this case:

The Cheating Spouse. It is Sunday morning, and a wife asks her husband, "Where were you last night?" Her husband replies, "I was out with the guys at Freddies Bar." He was indeed at the bar from 10$11 \mathrm{pm}$. Afterwards, though, he went back to the apartment of someone he met at the bar.

Now strictly speaking there is no distorting of the facts in this reply. He was out with the guys at Freddies Bar. But the distorting comes with the inference that the speaker intentionally wants his spouse to draw. His hope is that she will conclude, "He was only out with the guys at Freddies Bar." That clearly distorts the facts.

This case serves to illustrate that the distortion need not be limited to the literal content of what is said, but can include the manner and context

12 As MacIntyre writes, "successful liars necessarily deceive us not only about the subject matter about which they lie, but also about their own beliefs and about their intention in asserting what they assert falsely, and indeed about their further intention to conceal this intention from us" (1994: 313-314). See also Tollefsen 2014: 20, 47.

In our example, the teacher may also believe that Smith intends for the teacher to believe that the dog ate his homework. This, though, is a true belief. For relevant discussion, see Guenin 2005: 181. 
in which it is said too. If some of his co-workers ask him, "Which bar did you go to last night?" and he replies, "I was out with the guys at Freddies Bar," there is nothing distorting here with respect to either the content or the manner of delivery. But if he uttered the exact same words in a different context with his wife while also withholding some important information, and he thereby aimed at giving a true response that he hoped would lead her to arrive at a false conclusion, then there is something clearly distorting going on.

Also, misleading others need not be limited to verbal behavior. Painting over the rust on a used car before trying to sell it, also counts as misleading. ${ }^{13}$ And clearly it involves intentionally distorting the facts.

The approach can handle some non-standard cases too, such as intentionally making a false statement in order to get someone else to believe something true:

The Skeptical Friend. A's friend B is very skeptical of what A has to say about important matters. A knows about this skepticism. So one day he tells B that "Pluto is still considered one of the nine planets by astronomers." A knows this is false, but hopes to get B to believe the opposite, which is true. Low and behold, B does form the belief that Pluto is now no longer considered to be one of the nine planets by astronomers.

It is not clear whether this counts as a lie or a case of misleading or some third category. ${ }^{14}$ But it seems clear that it is a failure of honesty. That is captured by A's intentionally distorting the facts.

One final note. The "intentionally" is important in cases involving misleading others. Suppose that the same person had said in a clear voice, "I was out with the guys at Freddies Bar," but his wife misheard him as saying "I was out with the guys at Froggies Bar." Then there is a distortion of the facts involved, to be sure. But it isn't an intentional distortion on the husband's part, and so with respect to the name of the bar, it does not count as a case of dishonesty. ${ }^{15}$

Lying and misleading fit comfortably with the account in (H2). Other failures of honesty, such as cases of cheating, stealing, and promise-breaking, introduce interesting complexities, and I have discussed them at length

13 Carson 2010: 57.

14 For it not being a lie, see Guenin 2005: 183. For Augustine on cases like these, see Griffiths 2004: 28-29 and Decosimo 2010: 664-665. For related discussion, see Tollefsen 2014: 15-16.

15 For related discussion, see Carson 2010: 47. 
elsewhere. ${ }^{16}$ In the remaining sections of this article, I take up two important challenges to the account.

\section{Nazi at the Door Cases}

If (H2) or one of its close variants is meant to offer necessary conditions for honesty, then it looks like any distortion of the facts is going to count as a failure to be honest, at least in that one case. But perhaps there are cases where it is compatible with the virtue of honesty to intentionally distort the facts. Lying provides the most straightforward and widely discussed cases. Despite earlier arguments by Augustine and Kant, as well as some recent work, ${ }^{17}$ most contemporary philosophers seem to hold that situations arise in life in which lying is morally permissible and even morally obligatory. Lying to the Nazis in order to protect the Jews you are hiding in your house is the standard example. Kant's example of lying to the ax-murderer to save his would-be victim is another. ${ }^{18}$

The same possibility of morally permissible cheating arises as well, such as the following:

The High-Stakes Game. The well-being of a child hangs on the outcome of a card game. If Chase wins, he will be able to buy the child from the sex-traffickers and bring her back to her family. If he loses, she will be taken away and it will be very hard to ever find her again. Chase is an expert card sharp. When he tries to play the game fairly, he starts to lose badly. His only chance of winning is to start cheating, which he does. As a result, he wins the game and buys the child's freedom.

Chase clearly cheats, but arguably his doing so is morally permissible. There were also cases of morally permissible stealing, such as this:

The Hurricane. To stop a hurricane from destroying their house with their children inside, a couple might steal some unused plywood in their neighbor's yard, even though it will be unreturnable after the storm hits.

Even though the couple is fully aware that it was rightfully the neighbor's plywood, it seems that competing considerations could morally justify their taking it in a situation like this one.

16 See Miller in progress. There I also consider the relationship between bullshit and honesty.

17 See Finnis 1980, Murphy 1996, Garcia 1998, and Griffiths 2004.

18 For additional examples, see LaFollette and Graham 1986: 8-13, Guenin 2005: 207, and Stokke forthcoming. 
Let's assume in this section that there are cases of morally permissible lying, cheating, stealing, and so forth. Can my approach accommodate them? A natural revision to make to $(\mathrm{H} 2)$ is something like this:

(H3) The virtue of honesty is, centrally, a character trait concerned with reliably not intentionally distorting the facts as the agent sees them, so long as the agent does not take it to be morally permissible to do so.

Note that, in the spirit of (H2), this is a subjective way of developing the exception. On a more objective approach, we could say:

$\left(\mathrm{H}^{*}\right)$ The virtue of honesty is, centrally, a character trait concerned with reliably not intentionally distorting the facts as the agent sees them, so long as it is not morally permissible to do so.

It would then be the job of different ethical theories to tell us when it is or is not morally appropriate to lie, cheat, or steal. Standard utilitarianism will have a very different answer to give than standard forms of virtue ethics or divine command theory. ${ }^{19}$

Matters are more complicated than this, however. Let me focus just on the case of lying to focus the discussion, but what I say in the remainder of this section generalizes. We should distinguish between two different views about how honesty and morally permissible lying are related:

(i) The virtue of honesty does not apply to certain cases of lying, say lying to the Nazi in order to protect a Jewish family.

(ii) Lying in certain cases, such as to the Nazi in order to protect a Jewish family, is still a failure of honesty, but it is all-things-considered morally permissible.

One way to develop the thought behind (i) is along the following lines. Suppose that in order to count as a lie, it has to be the case that one's intended audience has a right to know the truth. Without that right, there is no lie, even if I say something I know to be false with the intention of deceiving my audience..$^{20}$ In the case in question, the thought would be that the Nazi has no right to know the whereabouts of the Jews he intends to harm. Hence telling the Nazi a bogus location of where the Jews are, would not fall under the purview of the virtue of honesty in this case since it does not count as a genuine lie.

19 For relevant discussion, see Fried 1978: chapter three, Gert 1998: chapter eight, Garcia 1998: 521, and Carson 2010.

20 For relevant discussion, see Bok 1979: 14-15, Carson 2010: 18-20, and Tollefsen 2014: 25-30. Benjamin Constant is said to hold the view above (MacIntyre 1994: 341), as did Grotius (Tollefsen 2014: 6). 
Another way to develop the thought behind (i) is to grant that telling the Nazi the wrong location would indeed be a lie, but that other considerations about the well-being of the Jews simply silence or eliminate consideration of the moral status of lying.

Initially when I was revising (H2), I assumed that something like this option in (i) was the case. But that is not obvious. According to (ii), someone hiding the Jews would indeed be telling a lie, the lie is morally justified, and the person is being dishonest. It is just that other virtues, such as benevolence or non-malevolence, take greater priority in such instances, and end up justifying lying all-things-considered. ${ }^{21}$

If we go with option (ii), then no revision to (H2) is needed after all. ${ }^{22} \mathrm{We}$ could say that in the Nazi case there are still normative facts pertaining to the pro tanto wrongness of lying, but those normative facts are being outweighed by other normative facts having to do with benevolence, for instance. ${ }^{23}$

Which option is more plausible? I do not have to take a stand, and could leave it up to the reader to decide. If it is (i), then a revision to (H2) has been provided above to accommodate it. If it is (ii), then no revision is needed.

For what it is worth, let me report that my sympathies have come to rest with (ii) and the claim that even morally justifiable lying (and cheating, stealing, and the like) is a failure of honesty. For one thing, it seems intuitively obvious to me that the person would be telling a genuine lie in intentionally giving a false location to the Nazi at the door. This intuition is fallible, and

21 I put this in terms of virtues, but the point can be put more neutrally just in terms of other morally relevant considerations which take greater priority than not intentionally distorting the facts. One implication of putting the point in terms of virtues, is that it seems like it would lead to a denial of the unity of the virtues thesis. Like most philosophers working on virtue, I find this to be an implication that is perfectly acceptable. Thanks to an anonymous reviewer for pointing it out.

22 Thanks to David Carr for relevant discussion.

23 Following Rosalind Hursthouse, one way to develop this thought further is in terms of what she calls resolvable moral dilemmas, which despite being resolvable often are such that "the overridden requirement retains its force in some way, so regret, or perhaps the recognition of a new requirement, are still appropriate" (1999: 44). Similarly, Christopher Tollefsen describes "the sense in which our brokenness and sinfulness - indeed, not just our own, but that of the world - makes it impossible for us to avoid sin; there are genuine cases of necessity in which one must act in a way that is imperfect, guilty sinful - yet nevertheless, to repeat, one must act in that way (Tollefsen 2014: 62, emphasis his; see also $61,68,71-72)$.

Note, though, that the Nazi case is not a moral dilemma in the strict sense of being required to perform two actions which cannot be jointly performed and where the moral requirements do not outweigh each other. Furthermore, it does not rise to the level of what Hursthouse calls a "tragic" moral dilemma, which can be resolvable or irresolvable on her view. In those dilemmas, "a virtuous agent cannot emerge with her life unmarred" (79). 
there may be powerful theoretical considerations that could force me to give it up, but I have yet to see them. ${ }^{24}$

Leaving aside the no-right-to-truth option, more generally it seems that (ii) is more intuitively plausible than (i). If I am asked - is lying to the Nazi a case where honesty just did not apply at all, or is it a case where the person did something dishonest but it was still justified overall? - I find the second option more compelling. In a similar vein, Tom Carson gives us this medical case:

Suppose that a man has just had open heart surgery and is temporarily in a precarious state of health. His surgeon says that he must be shielded from any emotional distress for the next few days. Unbeknownst to the patient, his only child, Bob, has been killed in an automobile accident. When the patient awakens after the surgery, he is surprised that Bob is not there and asks, "Where is Bob?" You fear that in his condition, the shock of learning about Bob's death might cause the man to die. So you lie and say that his son has been delayed...This seems to be a case of morally permissible lying that violates someone's right to know the truth. ${ }^{25}$

And I might add, it seems to be a case where you would be doing something dishonest. While I do not have any data to support this, I suspect my intuitions are in line with ordinary discourse and folk psychology here.

A third reason is theory-driven - if failing to be honest is, at its core, a matter of intentionally distorting the facts, then lying to the Nazi or the ax-murderer is no less a matter of intentionally distorting the facts than is morally prohibited lying. There is the same basic failure when it comes to

24 As Tom Carson writes about this case, "Ordinary language counts the example in question as a case of lying. There is a strong presumption against any definition of lying so much at odds with ordinary language. Using the term 'lying' in accordance with this definition is likely to engender confusion" (2010: 19). He provides additional arguments against this approach as well at 2010: 19-20, and see also Tollefsen 2014: 25-30, 90-92, and chapter three.

25 Carson 2010: 19-20. Similarly, cases of lying under duress support (ii) as well. Here is one such case from Stuart Green:

Imagine that $\mathrm{A}$, while having a gun held to his head by $\mathrm{B}$, is forced to lie to $\mathrm{C}$, who is on the other end of the telephone. A has done something wrongful; he has misled $\mathrm{C}$, and he has done so intentionally; he has acted unjustifiably. But A has acted under duress. Although A's act itself was wrongful, most of us would agree that he should not be blamed for it - that A's conduct, in other words, should be excused (2006: 84).

I would only add to its being wrongful that A's action was also dishonest, yet still allthings-considered morally permissible. Note that here too this does not require a revision to $\mathrm{H} 2$, since the duress bears on the blameworthiness and the all-things-considered moral permissibility of the lie, but not on its being a failure of honesty. Thanks to an anonymous reviewer for encouraging me to clarify this. 
conveying what reality (as the person sees it) is like. So it is hard to see why the scope of honesty would fall short of these lies.

Finally, a fourth reason is that (ii) parallels how other virtues work. Suppose just for the sake of discussion that torturing a terrorist in order to disclose the location of a bomb is all-things-considered morally justified. Nevertheless, the act itself is cruel, and is a failure of non-malevolence. The virtue term applies, but the relevant considerations - we are supposing - get outweighed.

But I don't have to close off options here. While I personally prefer (ii), one of my main goals is to get a number of possible views out on the table.

\section{The Challenge of Radically Mistaken Beliefs about Moral Norms}

A different challenge to $(\mathrm{H} 2)$ has to do specifically with its treatment of cheating and stealing. Consider cases such as this:

The Fight. Atticus has been forcibly enslaved and thrown into the coliseum to fight against the Roman gladiator for the entertainment of the crowd. Atticus is not given a fair chance; he only has a wooden shield to use against the armor and sword of the gladiator. But he manages to sneak in a small piece of metal which, at a key moment in the battle, he uses to cut the gladiator's throat. This is against the rules, and the crowd boos and calls Atticus a cheater.

Did Atticus cheat? In a sense, he did. He intentionally violated the rules governing this activity. This is the "factual" or "descriptive" sense in which Atticus cheated, even though objectively speaking he might not have done anything wrong. Hence it might seem on initial inspection that according to $(\mathrm{H} 2)$, Atticus's killing the gladiator constitutes a failure of honesty since he intentionally distorted the facts of what constitutes participating in this activity.

But that might seem implausible. The rules set up for this fight were blatantly unjust. Why should Atticus's honesty be faulted when he fails to follow those rules, thereby saving his own life in the process? ${ }^{26}$

Fortunately (H2) doesn't have to have this implication. For Atticus was not distorting the facts with respect to what he considered to be a fair fight. He was distorting the facts according to the people who controlled him, but not according to his own lights.

Cases of stealing present similar challenges for (H2). Take by way of illustration an abolitionist helping to secretly rescue a slave from a plantation.

26 As Green writes about another, related case: "it would not have been cheating for a girl in Afghanistan under the Taliban to violate the law that made it a crime for her to attend school, since the law itself was surely unjust and issued by an illegitimate authority" (2006: 63). 
Again there is a "descriptive" sense of stealing at work here. Given the prevailing social norms and laws of the time and place, what the abolitionist was doing would count as theft. Yet it is also hard to call such an abolitionist "dishonest" even though he was distorting the "facts" in society at the time about property rights.

However, the abolitionist presumably did not accept that what were said to be the "facts" about property ownership and slavery at the time, really were facts. So in helping to free the slave, he was not distorting the facts by his lights. On (H2), this would not count as failing to exhibit honesty.

But when we turn to the famous case of Huck Finn in Mark Twain's novel, matters are more complicated. During the time of slavery in the American South, Huck is faced with a choice between turning his friend Jim in to the authorities as a runaway slave, or helping Jim to escape. He ends up doing the latter. But Huck clearly thinks that what he is doing is morally wrong, that it constitutes stealing from Jim's "master." He judges that he should turn Huck in, and when he doesn't do so, he considers himself a bad boy. Yet clearly he is not. Twain depicts Huck Finn as more practically wise and perceptive - in a word, more virtuous - that many of the adults of that society. ${ }^{27}$

Does (H2) give the wrong verdict here? Since it ties honesty to not distorting the facts as the person sees them, and since Huck judges the facts (both descriptive and normative) to require him to turn Huck in, (H2) seems to imply that Huck failed to be honest in this one instance. Even if that evaluation is compatible with Huck Finn's also being highly compassionate, caring, and even honest in many other situations, it still might be hard to accept. ${ }^{28}$

Fortunately, though, (H2) does not have to imply this about Huck. For while Huck was distorting certain "facts" by his lights, he was not distorting other ones. He was responding to his experience of what his friendship with Jim means to him, and how he had come to see Jim as a genuine person about whom he cared a great deal. Those strike me as facts too, even if they were not part of his consciously formed moral judgment.

So in helping Jim, Huck was distorting certain facts by his own light, but not distorting other facts. And the ones that were truly more important to him were the ones that went against his conscious moral judgment to turn Jim in. So relative to the facts about which he cared the most, he was not failing to be honest.

This can lead to another revision to (H2), where someone's honesty is relativized to various kinds of norms:

27 Here I have been helped by Arpaly 2002.

28 As noted in footnote 7, even though (H2) is an account of the trait of honesty, it still has implications for what it is to succeed or fail at performing a particular honest action. And if it would suggest that Huck Finn failed to exhibit honesty in this one case, then many will see that as a drawback of the account. 
(H4) The virtue of honesty is, centrally, a character trait concerned with reliably not intentionally distorting the facts as the agent sees them, including what the agent takes (either consciously or unconsciously) to be the normative facts thought to be relevant in a given situation. If the agent takes there to also be opposing normative facts which bear on the situation, then she may be honest or fail to be honest in relation to each set of normative facts. In addition, she may be honest or fail to be honest in relation to the normative facts all-things-considered. ${ }^{29}$

It seems intelligible to say that relative to the societal norms of his day which Huck used in forming his conscious judgment, he failed to exhibit honesty by subsequently helping Jim to escape. But relative to his more deeply held norms of friendship and caring for Jim, his behavior did not fail.

Similarly, returning to the case of Atticus and the gladiator, (H6) can capture what we called the "descriptive" sense in which Atticus was a cheater. Relative to the social norms for fights like these in ancient Rome, his behavior distorted the normative facts. He was not allowed to bring a weapon into the arena. But (H6) can also capture the sense in which he did not do anything dishonest, namely relative to what he took to be the normative facts having to do with justice and with his own self-preservation.

(H4) also serves to emphasize that even though honesty is still being understood using a subjective approach to thinking about the facts, for the agent in question they need not be part of her conscious awareness in the moment.

As far as this paper in concerned, (H4) is the final revision of the account of honesty that will be considered.

\section{Conclusion}

In this paper I have begun the work of developing and defending an original account of the virtue of honesty. Even though the account went through multiple revisions, there is still much more work that needs to be done. Motivation, for instance, is not addressed by (H4) at all. But hopefully important progress has been made in these largely uncharted philosophical waters. ${ }^{30}$

29 Connecting failures of honesty to distortions of the normative as well as the descriptive facts, has a number of important and controversial implications that I have explored in some detail in Miller in progress. One such implication, for instance, is that every case of morally wrong behavior which is taken by the agent to be morally wrong, will also count as dishonest.

30 I am very grateful to Voin Milevski for inviting me to be a part of this special issue and to two anonymous reviewers for very helpful comments. Work on this paper was supported by a grant from the John Templeton Foundation and from the Templeton Religion Trust. The opinions expressed here are those of the author and do not necessarily reflect the views of these Templeton Foundations. 


\section{Works Cited}

Arpaly, Nomy. (2002). Unprincipled Virtue. New York: Oxford University Press.

Bok, Sissela. (1978). Lying: Moral Choice in Public and Private Life. Pantheon Books.

Bratman, Michael. (1987). Intention, Plans, and Practical Reason. Cambridge, MA: Harvard University Press.

Caouette, Justin and Carolyn Price. (2018). The Moral Psychology of Compassion. Lanham: Rowman and Littlefield.

Carson, Thomas. (2010). Lying and Deception: Theory and Practice. Oxford: Oxford University Press.

Decosimo, David. (2010). "Finding Augustine's Ethics of Public Lying in His Treatments of Lying and Killing." Journal of Religious Ethics 38: 661-697.

Driver, Julia. (1989). “The Virtues of Ignorance." Journal of Philosophy 86: 373-384.

Finnis, John. (1980). Natural Law and Natural Rights. Oxford: Oxford University Press.

Fried, Charles. (1978). Right and Wrong. Cambridge: Harvard University Press.

Garcia, J. L. A. (1998). "Lies and the Vices of Deception." Faith and Philosophy 15: 514-537.

Gert, Bernard. (1998). Morality: Its Nature and Justification. Oxford: Oxford University Press.

Guenin, Louis. (2005). “Intellectual Honesty.” Synthese 145: 177-232.

Green, Stuart. (2006). Lying, Cheating, and Stealing: A Moral Theory of WhiteCollar Crime. Oxford: Oxford University Press.

Griffiths, Paul. (2004). Lying: An Augustinian Theology of Duplicity. Grand Rapids: Brazos Press.

Hursthouse, Rosalind. (1999). On Virtue Ethics. Oxford: Oxford University Press.

LaFollette, Hugh and George Graham. (1986). "Honesty and Intimacy." Journal of Social and Personal Relationships 3: 3-18.

MacIntyre, Alasdair. (1981). After Virtue. Notre Dame: University of Notre Dame Press.

MacIntyre, Alasdair_. (1994). "Truthfulness, Lies, and Moral Philosophers: What Can We Learn from Mill and Kant?" The Tanner Lectures on Human Values 16: 308-361. 
Mele, Alfred. (1995). Autonomous Agents: From Self Control to Autonomy. Oxford: Oxford University Press.

Miller, Christian. (2017). "Honesty," in Moral Psychology, Volume V: Virtue and Character. Ed. Walter Sinnott-Armstrong and Christian B. Miller. Cambridge: MIT Press, 237-273.

Miller, Christian. (in progress). Honesty: The Philosophy and Psychology of a Neglected Virtue.

Miller, Christian and Ryan West. (Forthcoming). Integrity, Honesty, and Truth Seeking. Ed. Christian B. Miller and Ryan West. New York: Oxford University Press, forthcoming.

Murphy, Mark. (1996). "Natural Law and the Moral Absolute Against Lying." American Journal of Jurisprudence 41: 81-101.

Smith, Tara. (2003). "The Metaphysical Case for Honesty." The Journal of Value Inquiry 37: 517-531.

Stokke, Andreas. (Forthcoming). "Lies, Harm, and Practical Interests." Philosophy and Phenomenological Research https://doi.org/10.1111/phpr.12439.

Tollefsen, Christopher. (2014). Lying and Christian Ethics. Cambridge: Cambridge University Press.

Wilson, Alan. (2018). "Honesty as a Virtue." Metaphilosophy 49: 262-280. 